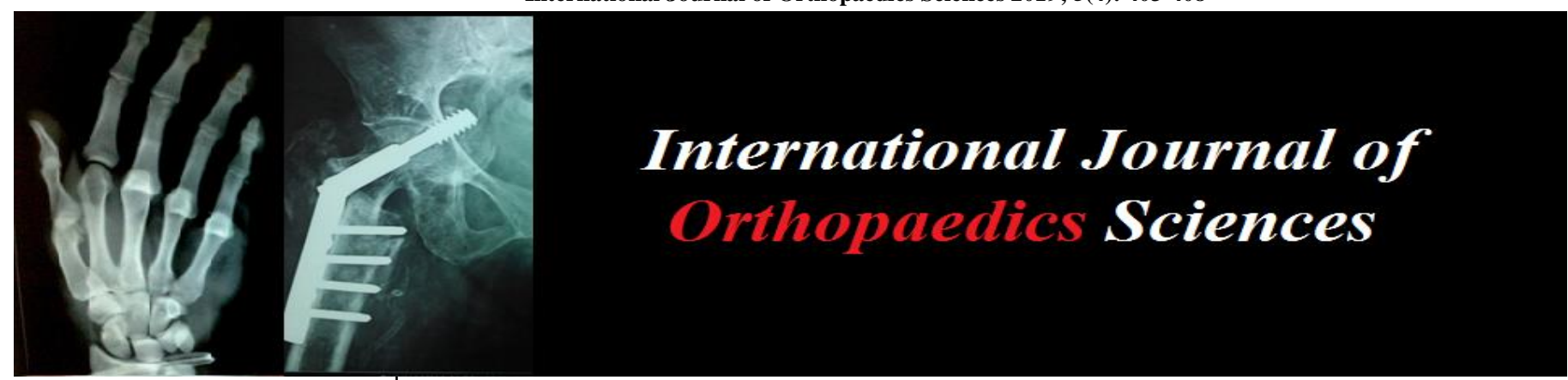

E-ISSN: 2395-1958

P-ISSN: 2706-6630

IJOS 2019; 5(4): 403-408

(C) 2019 IJOS

www.orthopaper.com

Received: 24-08-2019

Accepted: 28-09-2019

Dr. Ashwini Gaurav

Senior Resident, Patna Medical

College \& Hospital, Ashok

Rajpath, Patna, Bihar, India

Dr. Ranjit Kumar Singh

Associate Professor, Patna

Medical College \& Hospital,

Ashok Rajpath, Patna, Bihar,

India
Corresponding Author: Dr. Ranjit Kumar Singh Associate Professor, Patna Medical College \& Hospital, Ashok Rajpath, Patna, Bihar, India

\section{Hemiarthroplasty or total hip arthroplasty in fracture neck of femur? A dilemma in young elderly}

\author{
Dr. Ashwini Gaurav and Dr. Ranjit Kumar Singh
}

DOI: https://doi.org/10.22271/ortho.2019.v5.i4g.1706

\section{Abstract}

The debate over the preference of total hip arthroplasty (THA) over hemi hip arthroplasty (HHA) for displaced fracture neck of femur has been going on for decades, with studies in favour and against of both. We have done a study with three years follow up in fracture neck of femur patients. We have divided all patients into early and late presenters (cut off 6 weeks) and then observed the results of THA and HHA in all four groups. This could be a more specific deciding factor in choosing a correct implant for surgery. The shortcoming of our study was the small sample size and the short observation period. The early presenters $(<6$ weeks) and late presenters $(>6$ weeks) were randomly allocated to undergo THA or HHA. These were then followed up for 3 years to observe the effectiveness of the operative procedure, assess the post-operative radiographs, functional outcome, the rate and cause of revision surgeries and the rate and cause of mortality of patient. In comparison to HHA, THA had longer duration of surgery and more blood loss. But, both the surgery had almost similar mortality rates (10\% vs. 8.57\%). Limb lengthening was more common in THA group in both early and late presenters. Although more THA patient were ambulant immediately after surgery, but after 3 years the rates were similar in both THA and HHA group. The Harris Hip Score was always better in THA than HHA group in both early (mean 78.69 vs 70.72$)(\mathrm{p}=0.0005)$ and late (mean 73.58 vs 64.75$)(\mathrm{p}=0.041)$ presenters. In our study there was no progression of osteolysis in Early THA and Early HHA group at the end of 3 years. In the Late THA group $50 \%$ and late HHA group $18 \%$ of patients migrated from adequate cementation to inadequate cementation at the end of 3 years. It was concluded that THA had better results in early presenting cases with one having some advantage over the other; but, in late presenting patients THA definitely had advantage of more pain relief, better function and less revisions.

Keywords: Neck of femur fractures, total hip arthroplasty, hemi hip arthroplasty

\section{Introduction}

Fracture of the femur neck is also called "a fracture of necessity" among the Orthopaedic fraternity, in other words it is a kind of fracture that has to be operated upon for optimal results. Optimum treatment for fracture neck of femur in elderly has been a matter of debate since long and many studies have shown that replacing the head is a better choice than trying to save the head. The goal of treatment of these fractures is the restoration of pre-injury function, without associated morbidity. Although both Hemiarthroplasty and Total Hip Arthroplasty are approved treatments for displaced femoral neck fractures, in the physiologically elderly, the most common treatment is to perform a Hemiarthroplasty. However, in a select group of hip fracture patients who have concurrent osteoarthritis or rheumatoid arthritis, a Total Hip Arthroplasty has been the treatment of choice. The improved functional capacity and greater predictability of Total Hip Arthroplasty prostheses have broadened the indications for joint arthroplasty surgery in displaced femoral neck fractures over recent years.

In light of possibly enhanced function following Total Hip Arthroplasty, the question now is whether there is a role for a Total Hip Arthroplasty, rather than Hemiarthroplasty, in ambulatory patients with displaced femoral neck fractures, even if the patient has a "normal" articular surface at the time of the fracture.

Another problem in underdeveloped places is late presentation of the patients to hospital, sometimes as late as 12 weeks in our study, probably due to poverty, bad transportation and overall negligent attitude of the attendants. 
These neglected fractures are not same as the fresh ones. The patient has been immobilised for a longer period and very frequently on radiographs, the neck is found to be resorbed and a thin shell of femoral head lying in the acetabulum.

Our study aimed to compare the results of THA and HHA done in both the early ( $<6$ weeks) and late presenting cases (>6weeks). The results could help in deciding the choice of surgery by the time of presentation of patients.

\section{Specific objectives of the study}

1. Effectiveness of the operative procedure - assessed by immediate post-operative pain relief and walking, limb length discrepancy and post-operative infections.

2. To assess the post-operative radiographs at the serial follow ups for femoral stem cementing quality and acetabular erosions.

3. Functional outcome of the operative procedure - assessed by "Harris Hip Score (HHS)".

4. Time taken to return back to normal living - assessed by ambulation rate of the patients with/without support.

5. To assess the rate and cause of revision surgeries.

6. To assess the rate and cause of mortality of patient, if any.

\section{Materials and Methods}

Study Area: Department of Orthopaedics, Patna Medical College \& Hospital, Patna, India

Study Population: Patients attending the outpatient and emergency department with displaced fracture neck of femur.

\section{Inclusion criteria}

- Patients with displaced fracture neck of femur (Garden Type III and IV).

- Age group between 60 to 80 years of age.

- Patients were initially ambulating before the fractures.

- Patients with sound state of mind with no psychiatric treatment going on.

- Patients with no other diseases that would limit the patient to bed after operation.

\section{Exclusion criteria}

- Patients with ipsilateral femoral shaft fractures.

- Patients with any fracture of long bones in the lower extremity.

- Patients with fractures of spine.

- Any Intra-thoracic or Intra-abdominal injuries, i.e., polytrauma patients.

- Patients with diagnosed renal Osteodystrophy, Osteomalacia, or pathologic fracture (i.e., malignancy). In patients with underlying concomitant comorbid conditions which predispose to severe osteopenia the outcome of surgery maybe significantly different.

Study period: May 2011 to September 2017

Sample Size: A total of 55 patients with fracture neck of femur were admitted into the trial. Out of which 20 were treated with Total Hip Arthroplasty (THA) and 35 with Bipolar Hemi Hip Arthroplasty (HHA)

Sample Design: Simple Random Sampling.

Study Design: Prospective Study.

Study Tools: Total Hip Arthroplasty set: Cemented Femoral stem \& Uncemented Acetabular cup; Metal head on Polyethylene liner; same manufacturer.

Hemi Hip Arthroplasty set: Cemented, Non modular; same manufacturer.
Study Techniques: The study was conducted in the Department of Orthopaedics, Patna Medical College and Hospital. All the patients received verbal and written information about the purpose and procedure of the study and written informed consent was obtained

Plan of Analysis of Data: The total numbers of patients were first divided into those presenting early (within 6 weeks) and late (after 6 weeks). Then again they were selected randomly to undergo Total Hip Arthroplasty (THA) and Bipolar Hip Hemi Arthroplasty (HHA). Total four groups were formed after the collection of data:

1. EARLY THA - THA done in patients presenting within 6 weeks.

2. EARLY HHA - HHA done in patients presenting within 6 weeks.

3. LATE THA - THA done in patients presenting after 6 weeks.

4. LATE HHA - HHA done in patients presenting after 6 weeks.

\section{Results}

The patients were minimum followed up for 3 years. A total of 55 patients were admitted, out of which 9 patients were excluded from the observational data due to loss of follow up or death. 46 patients were taken as total for computing all data, except the mortality rate which was computed on total 55 cases.

The average age of patient, was 72.39 years. A total of 26 males $(56.5 \%)$ and 20 females $(43.47 \%)$ were admitted. The frequency of fracture went from being more common among males $(80 \%)$ in the earlier age group, to being more common among females $(56.25 \%)$ in higher age group. Average duration of surgery and average blood loss are given in table 1 .

Ambulation at day 1 and then at 3 years (assisted and independent), post-operative infection rate and revision rate are given in table 2 . A cut off of $1 \mathrm{~cm}$ was decided as any lengthening below $1 \mathrm{~cm}$ could be compensated by pelvic tilt and go unnoticed and would not cause any discomfort to the patient. The results are given in table 2 .

Femoral stem cement evaluation was done at day 0,1 year and 3 years by "Barrack Femoral component cementation

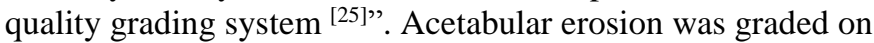
the basis of its radiographic appearance given by "Baker" ${ }^{30 "}$. Both the results are given in table 3 and 4 respectively. We have chosen the "Harris Hip Score" system for evaluation of mid-term clinical outcomes and the results are given in table 5.

The cause of revision surgeries in all patients were looked into and found. 2 patients in the early HHA group had hip pain, 1 patient in Late THA had infection and femoral stem loosening, while, in late HHA 1 patient required revision for hip pain and 2 patients for hip pain and infection. The mortality rates are given in table 1 . The deaths among the Total Hip Arthroplasty group were due to cardiovascular complications. In the Bipolar Hemiarthroplasty group the deaths were due to cardiovascular complications and due to uncontrolled diabetes.

Table 1: Perioperative data

\begin{tabular}{|c|c|c|}
\hline & THA & HHA \\
\hline Duration of Surgery & $126.88 \mathrm{~min}$ & $90.26 \mathrm{~min}$ \\
\hline Average Blood loss & $412.5 \mathrm{ml}$ & $226.25 \mathrm{ml}$ \\
\hline Mortality & $10 \%$ & $8.57 \%$ \\
\hline
\end{tabular}


Table 2: Postoperative data

\begin{tabular}{|c|c|c|c|c|}
\hline & EARLY THA & EARLY HHA & LATE THA & LATE HHA \\
\hline Total cases & 13 & 18 & 12 & 12 \\
\hline Limb Lengthening > 1 cm & $15.3 \%$ & $11.11 \%$ & $16.66 \%$ & $0 \%$ \\
\hline Ambulation at Day 1 (Assisted) & $76.9 \%$ & $72.22 \%$ & $66.66 \%$ & $50 \%$ \\
\hline Ambulation at 3 Years (Total) & $100 \%$ & $94.44 \%$ & $91.66 \%$ & $91.66 \%$ \\
\hline Ambulation at 3 Years (Assisted) & $25 \%$ & $5.55 \%$ & $8.33 \%$ & $16.66 \%$ \\
\hline Post-Operative infection & $0.07 \%$ & $0.05 \%$ & $8.33 \%$ & $16.66 \%$ \\
\hline Revision Surgery & $0 \%$ & $11.11 \%$ & $8.33 \%$ & $25 \%$ \\
\hline
\end{tabular}

Table 3: Femoral stem cement evaluation by Barrack's grading system

\begin{tabular}{|c|c|c|c|c|}
\hline & EARLY THA & EARLY HHA & LATE THA & LATE HHA \\
\hline Day 0 & $\begin{array}{l}\text { Grade A - } 75 \% \\
\text { Grade B - } 25 \%\end{array}$ & $\begin{array}{l}\text { Grade A - } 66.6 \% \\
\text { Grade B - } 16.6 \% \\
\text { Grade C - } 16.6 \%\end{array}$ & $\begin{array}{c}\text { Grade A - 50\% } \\
\text { Grade B - } 33.3 \% \\
\text { Grade C - } 16.6 \%\end{array}$ & $\begin{array}{c}\text { Grade A - } 66.6 \% \\
\text { Grade B - } 25 \% \\
\text { Grade C - } 8.3 \%\end{array}$ \\
\hline Year 3 & $\begin{array}{l}\text { Grade A - } 50 \% \\
\text { Grade B - 50\% }\end{array}$ & $\begin{array}{l}\text { Grade A - } 55.5 \% \\
\text { Grade B - } 27.7 \% \\
\text { Grade C - } 16.6 \%\end{array}$ & $\begin{array}{c}\text { Grade A - 50\% } \\
\text { Grade B - 33.3\% } \\
\text { Grade C - } 8.3 \% \\
\text { Grade D - } 8.3 \%\end{array}$ & $\begin{array}{c}\text { Grade A - } 58.3 \% \\
\text { Grade B - } 16.6 \% \\
\text { Grade C - } 25 \%\end{array}$ \\
\hline
\end{tabular}

Table 4: Radiographic evaluation for acetabular erosion by Baker

\begin{tabular}{|c|c|c|c|c|}
\hline & EARLY THA & EARLY HHA & LATE THA & LATE HHA \\
\hline 6 Months & $100 \%$ - Grade 0 & $100 \%$ - Grade 0 & $100 \%$ - Grade 0 & $100 \%$ - Grade 0 \\
\hline \multirow{2}{*}{ 3 Years } & $100 \%$ - Grade 0 & $88.8 \%$ - Grade 0 & \multirow{2}{*}{$100 \%$ - Grade 0} & $75 \%$ - Grade 0 \\
& & $11.1 \%$ - Grade 1 & $25 \%$ - Grade 1 \\
\hline
\end{tabular}

Table 5: Harris Hip Score (Mean)

\begin{tabular}{|c|c|c|c|c|}
\hline & EARLY THA & EARLY HHA & LATE THA & LATE HHA \\
\hline 3 YEARS & 78.69 & 70.72 & 73.58 & 64.75 \\
\hline
\end{tabular}

\section{Discussion}

The discussions regarding the preferred implant in fracture neck of femur patients has been going on since decades. The three choices of Osteosynthesis, hemi hip arthroplasties and total hip arthroplasties have been discussed in many articles. In a study by Barnes [1] in 1976, out of 1183 displaced fractures (Type III \& IV) $33 \%$ fractures failed to unite and $27.6 \%$ of united fractures had late collapse of the head. Skinner ${ }^{[2]}$ in 1986 reported $23 \%$ failure in displaced fractures and $27 \%$ avascular necrosis after 3 years in those united by Osteosynthesis. The fate of Osteosynthesis in this age group has Lead to its unpopularity among surgeons. HHA and THA are more valid options that require further discussions. Squires ${ }^{[3]}$ in 1999 demonstrated, in a retrospective study, that THA performed for acute femoral neck fractures yielded $86 \%$ good or excellent results as compared to only $12 \%$ good or excellent results in a matched group of patients after HHA. Of the patients in the THA group $77 \%$ noted that they could walk over a mile, while only $27 \%$ of the patients in the HHA group could do the same. Bhandari ${ }^{[4]}$ in 2005 did cross sectional survey to map the preferences of North American surgeons for displaced fractures, and, THA was found to be preferred for obtaining better functions and more pain relief. Blomfeldt [5] in 2007 found The health-related quality of life measure was in favour of the total hip replacement group but did not reach statistical significance $(\mathrm{p}=0.818$ at four months and $\mathrm{p}=0.636$ at 12 months). These results indicate that a total hip replacement provides better function than a bipolar hemiarthroplasty as soon as one year post-operatively, without increasing the complication rate.

We have chosen the Harris Hip Score (HHS) System for evaluation of mid-term clinical outcomes because of its high validity and accuracy, but also for its easy comparison with other evaluation scales (Soderman Dai) ${ }^{[6,7]}$. Henning [8] deems that satisfactory and better clinical outcomes are over
50 points by HHS, but for Lestrange ${ }^{[9]}$, fair clinical outcomes are HHS values over 70 points. The study by Blomfeldt ${ }^{[5]}$ had better HHS in THA group (87.2) than HHA group (79.4) and also had significant improvement in HHS in THA group at 1 year. Macaulay ${ }^{[10]}$ in 2007 showed better HHS in THA (84) than HHA (81.1). Mouzopoulos ${ }^{[11]}$ in 2008 had similar results THA (83.7) vs. HHA (79.5). Van den Bekerom ${ }^{[12]}$ showed similarly in 2010 with HHS scores of 75.2 in THA and 71.9 in HHA. At the end of 3 years, we similarly had better results of HHS in THA in both early and late groups; 78.69 (Early THA) and 73.58 (Late THA) as compared to 70.72 (Early HHA) and 64.75 (Late HHA). THA had statistically significant better functional results in Early presenting cases (mean 78.69 vs 70.72$)(\mathrm{p}=0.0005)$ and also late presenting cases (mean 73.58 vs 64.75$)(\mathrm{p}=0.041)$. Our scores were less as compared to above studies, probably because of the noncompliance of the rural patients to strict physiotherapy protocols, still the patients with THA performed better in the HHS scoring.

In a study by Jaswinder Pal Singh Walia ${ }^{[13]}$ in $2012,96 \%$ of the THA patients and $100 \%$ of the HHA patients were complete weight bearing by 4 weeks. In our study THA had better pain relief immediately after surgery as the ambulation rates were higher on day 1 in both early (75\% vs. $72 \%)$ and late $(66 \%$ vs. $50 \%)$ presenters. At 3 years, in early group THA had more ambulatory patients than HHA (100\% vs. 94.4\%), whereas, it was same for both THA and HHA in Late group $(91.6 \%)$.

Schutzer SF ${ }^{[14]}$ in 1988 had $0.38 \%$ deep infection rate in THA done in 575 patients. The infection rate in a study by Philips ${ }^{[15]}$ in 2006 was only $0.57 \%$; he emphasised the advantage of doing the arthroplasties in a specialist hospital only. Pulido ${ }^{[16]}$ had similar results of $0.7 \%$ infection rate after THA and also that $65 \%$ of the cases occurred in the first year. A large study done on 1727 patients by Blom ${ }^{[17]}$ in 2003 had 
$1.08 \%$ infection rate in primary THA and was $2.1 \%$ in revision THAs. V K Chaplin ${ }^{[18]}$ reported $1.8 \%$ infection rate in a study done 490 cases. In a retrospective study of 150 patients in Tehran (2014) by Sadegh [19] showed $2.66 \%$ infection rate after HHA. In our study, there was no infection in the Early THA and Early HHA groups, while we had $8.33 \%$ and $16.66 \%$ infection rate in the Late THA and Late HHA group. This contrast in the infection rate in the late presenting cases can be due to a lengthier surgical time, more blood transfusions, Negligent attitude of the care giving attendants or due to the small sample size.

Campbell's operative orthopaedics book states and several studies have shown that Leg lengthening up to $1 \mathrm{~cm}$ is well tolerated and of more than approximately $1 \mathrm{~cm}$ frequently is a source of significant patient dissatisfaction despite an otherwise technically satisfactory operation. If lengthening exceeds $2.5 \mathrm{~cm}$, sciatic palsy and limping with a vaulting-type gait may result. In a study by C S Ranawat ${ }^{[20]}$ in 2007,100 hips were followed for LLD, 14\% had LLD after 1 month of surgery which reduced to $9 \%$ at 15 years follow up. Love and Wright ${ }^{[21]}$ reported up to $18 \%$ of patients had lengthening of more than $1.5 \mathrm{~cm}$, of whom $6 \%$ required shoe correction. Williamson and Reckling ${ }^{[22]}$ reported LLD of $16 \mathrm{~mm}$ in their series and up to $27 \%$ patients needed a shoe lift for correction. In a study by $\mathrm{H} \mathrm{K}$ Yoon ${ }^{[23]}$ in 2009 in post-operative lengthening after HHA found that Limb-lengthening by hemiarthroplasty may be a cause of pain but with little effect on the overall functional outcome. In our study, we had more cases with limb lengthening in THA group than HHA group (average $20.8 \%$ vs. $11.11 \%$ ) and more so in the early cases. Overall, THA is more susceptible to post-operative limb lengthening and can be a cause of dissatisfaction to the patients.

Table 6: Barrack's Grading System

\begin{tabular}{|c|c|}
\hline Grade A & Complete filling of medullary canal, without radiolucent lines between the cement and the bone (white out) \\
\hline Grade B & Radiolucent lines covering up to 50\% of the cement-bone interface \\
\hline Grade C & Radiolucent lines covering between 50\% and 99\% of the cement-bone interface or incomplete cement mantle \\
\hline Grade D & Complete radiolucent lines (100\%) at the cement-bone interface and/or absence of cement distally to the end of stem \\
\hline
\end{tabular}

The radiographic parameters used most often when assessing the quality of the cementation obtained in a hip arthroplasty include the homogeneity of the cement mantle ${ }^{[25,26]}$, its distal extension up to the end of the femoral stem ${ }^{[27]}$ and the presence of defects in the cement-bone interface ${ }^{[28]}$. A grading system that includes all of these parameters was proposed by Barrack ${ }^{[25]}$ to specifically evaluate the femoral component cementation and to identify stems with a risk of loosening. Chambers ${ }^{[29]}$ suggest the grading of the quality of cementation obtained with the Barrack system in only two categories: adequate cementation (Barrack A and B, not associated with early loosening) and inadequate cementation (Barrack C and D, associated with early loosening). In our study there was no progression of osteolysis in Early THA and Early HHA group at the end of 3 years. In the Late THA group $50 \%$ of patients with inadequate cementation progressed to Grade C to D over 3 years. In the late HHA group there was $18 \%$ patients migrated from adequate cementation to inadequate cementation (Grade C to D) at the end of 3 years. The late presentation of the patients lead to more inadequate cementation and progressive loosening for reason not understood. Radiographic evaluation for acetabular erosion was measured following the classification proposed by Baker ${ }^{[30]}$.

Table 7: Bakers's Classification

\begin{tabular}{|c|c|}
\hline \multicolumn{2}{|c|}{ Baker's Classification of Acetabular Erosion } \\
\hline Grade 0 & No erosion \\
\hline Grade 1 & Narrowing of articular cartilage, no bone erosion \\
\hline Grade 2 & Acetabular bone erosion and early migration \\
\hline Grade 3 & Protrusio acetabuli \\
\hline
\end{tabular}

The THA patients had no acetabular erosions but $11 \%$ of the early HHA and $25 \%$ of the late HHA group had erosions which were a cause of discomfort to the patients while walking. It was probably due to hard metal bipolar head articulating against the soft acetabular cartilage.

Various studies in the past have reported the dislocation rates between 3.5 to $22 \%$. In our study there was no dislocation in any patient in any group. Rogmark ${ }^{[31]} \&$ Blomfeldt $^{5}$ had reported similar results in their studies. The reason could be the strict adherence to the surgical principles and meticulous closure of posterior capsules and external rotator muscles The revision rates were higher in the HHA group in both early and late presenters. The assumed cause in late presenters was longer duration of surgery leading to higher infection rates and in hemiarthroplasty group acetabular erosions and pain that required revision surgeries. Squires ${ }^{[3]}$ had similar results of no revision of THA patients as compared to $38 \%$ in HHA patients at average 3.8 year follow up. These patients are being followed and a detailed revision status can be updated at 10 years.

The mortality rates were comparable in the THA and the HHA group ( $10 \%$ vs. $8.5 \%)$. Similar results were shown by Blomfeldt ${ }^{[5]}$ (6.7\% THA vs. 5\% HHA) and Burgers ${ }^{[32]}(13 \%$ THA vs. $15 \%$ HHA).

\section{Concluson}

\section{THA features}

- Statistically significant better Harris Hip Score in both groups than HHA

- More post-operative pain relief shown by higher ambulation rate on day 1 in both groups than HHA

- No acetabular erosions

- Lesser Revision Surgeries

- Longer duration of surgery

- More blood loss

- More limb lengthening

- Higher infection rate in late THA

- Progression of osteolysis in late THA

- Comparable mortality

- Comparable ambulation rate at 3 years

\section{HHA features}

- Shorter duration of surgery

- Less blood loss

- Less chances of limb lengthening

- Lower Harris Hip Score in both groups than THA

- Progression of osteolysis in late HHA

- Lesser post-operative pain relief shown by lower ambulation rate on day 1 in both groups than THA

- More acetabular erosions 
- Higher infection rate in late HHA

- Higher revision surgeries

- Comparable mortality

- Comparable ambulation rate at 3 years

Observing the above data, it has been concluded that in patients of fracture neck of femur presenting within 6 weeks, both THA and HHA could be performed, with THA having advantage of better functional results, slightly higher ambulation rates and less revisions, but with higher chances of limb lengthening and more blood requirement. But in the patients presenting after 6 weeks had definite advantage of THA with much less revision rates due high number of patients having hip pain in HHA group that required revision, higher HHS and lesser infection rates.

\section{References}

1. Barnes R, Brown JT, Garden RS, Nicoll EA. Subcapital fractures of the femur. A prospective review. J Bone Joint Surg Br. 1976; 58:2-24.

2. Skinner PW, Powles D. Compression screw fixation for displaced subcapital fracture of the femur. Success or failure? J Bone Joint Surg Br. 1986; 68:78-82.

3. Squires B, Bannister G. Displaced intracapsular neck of femur fractures in mobile independent patients: total hip replacement or hemiarthroplasty? Injury. 1999; 30:345-8.

4. Bhandari M, Devereaux PJ, Tornetta $\mathrm{P}$ et al. Operative management of displaced femoral neck fractures in elderly patients. An international survey. J Bone Joint Surg Am. 2005; 87:2122-30.

5. Blomfeldt R, Tornkvist H, Eriksson K, Söderqvist A, Ponzer S, Tidermark J. A randomized controlled trial comparing bipolar hemiarthroplasty with total hip replacement for displaced intracapsular fractures of the femoral neck in elderly patients. J Bone Joint Surg Br. 2007; 89:160-5.

6. Soderman P, Malchau H. Is the Harris Hip score system useful to study the outcome of total Hip replacement? Clin Orthop Relat Res. 2001; (384):189-97.

7. Dai KR, Dong F, Wang YY. Comparative study of three different hip function evaluation systems. Zhonghua Wai Ke Za Zhi. 1994; 32(9):535-8.

8. Henning F, Hoepffner HJ, Muth A. Indications for bipolar prosthesis in femoral neck fractures. A retrospective study of the prognosis in geriatric patients with bipolar prosthesis with reference to the preoperative health status. Unfallchirurg. 1991; 94(8):409-16.

9. Lestrange NR. Bipolar Arthroplasty for 496 hip fractures. Clin Orthop Relat Res. 1990; 251):7-19.

10. Macaulay W, Nellans KW, Garvin KL, Iorio R, Healy WL, Rosenwasser MP. Prospective randomized clinical trial comparing hemiarthroplasty to total hip arthroplasty in the treatment of displaced femoral neck fractures: winner of the Dorr Award. J Arthroplasty. 2008; 23(6/1):2-8.

11. Mouzopoulos G, Stamatakos M, Arabatzi H, Vasiliadis G, Batanis G, Tsembeli A et al. The four-year functional result after a displaced Subcapital hip fracture treated with three different surgical options. Int. Orthop. 2008; 32(3):367-373.

12. Van den Bekerom MPJ, Hilverdink EF, Sierevelt IN, Reuling EMBP, Schnater JM, Bonke $\mathrm{H}$ et al. A comparison of hemiarthroplasty with total hip replacement for displaced intracapsular fracture of the femoral neck: a randomized controlled multicentre trial in patients aged 70 years and over. J Bone Joint Surg Br. 2010; 92(10):1422-1428.

13. Jaswinder Pal Singh Walia, Avinash Chander Gupta, Kuldeep Sandhu, Sudhir Sethi, Sargun Singh, Anshul Dahuja. Follow up study of total hip arthroplasty and bipolar in intra-capsular fracture neck femur in elderly people - A study of 50 cases each. Pb Journal of Orthopaedics, 2012, 8(1).

14. Schrutzer SF, Harris WH. Deep-wound infection after total hip replacement under contemporary aseptic conditions. J Bone Joint Surg Am. 1988; 70(5):724-7.

15. Phillips JE, Crane TP, Noy M, Elliott TS, Grimer RJ. The incidence of deep prosthetic infections in a specialist orthopaedic hospital: a 15-year prospective survey. J Bone Joint Surg Br. 2006; 88(7):943-8.

16. Pulido L, Ghanem E, Joshi A, Purtill JJ, Parvizi J. Periprosthetic joint infection: the incidence, timing, and predisposing factors. Clin Orthop Relat Res. 2008; 466(7):1710-5.

17. Blom AW, Taylor AH, Pattison G, Whitehouse S, Bannister GC. Infection after total hip arthroplasty THE Avon Experience. J Bone Joint Surg [Br]. 2003; 85B:956-9.

18. Chaplin VK, Matharu GS, Knebel RWC. Complications following hemiarthroplasty for displaced intracapsular femoral neck fractures in the absence of routine followup. Ann R Coll Surg Engl. 2013; 95(4):271-274.

19. Sadegh Saberi, Aidin Arabzadeh, Bijan Khomeisi, Edris Berehnegard, Javad Mortazavi SM. Early Complications Following Bipolar Hemiarthroplasty for Femoral Neck Fracture in Elderly Patients. Acad. J Surg, 2014, 1(3-4).

20. Ranawat CS, Rodriguez JA. Functional leg-length inequality following total hip arthroplasty. J Arthroplasty. 1997; 12(4):359-64.

21. Love BRT, Wright K. Leg length discrepancy after total hip replacement. Proceedings of Australian Orthopaedic association. J Bone Joint Surg Br. 1983; 65:103.

22. Williamson JA, Reckling FW. Limb length discrepancy and related problems following total hip joint replacement. Clin Orthop Relat Res. 1978; 134):135-8.

23. Yoon HK, Kim BK, Chung JH, Han SC. The Relationship between Limb-Length Discrepancy on Function, Dislocation, Pain and Acetabular Wear after Bipolar Hemiarthroplasty for Femoral Neck Fracture. J Korean Hip Soc. 2009; 21(4):327-333.

24. Mulroy RD Jr, Harris WH. The effect of improved cementing techniques on component loosening in total hip replacement. An 11-year radiographic review. J Bone Joint Surg Br. 1990; 72(5):757-760.

25. Barrack RL, Mulroy RD Jr, Harris WH. Improved cementing techniques and femoral component loosening in young patients with hip arthroplasty. A 12-year radiographic review. J Bone Joint Surg Br. 1992; 74(3):385-389.

26. Roberts DW, Poss R, Kelley K. Radiographic comparison of cementing techniques in total hip arthroplasty. J Arthroplasty. 1986; 1(4):241-247.

27. Kobayashi S, Terayama K. Factors influencing survivorship of the femoral component after primary lowfriction hip arthroplasty. J Arthroplasty. 1992; 7:327-338.

28. Mulroy RD Jr, Harris WH. The effect of improved cementing techniques on component loosening in total hip replacement. An 11-year radiographic review. J Bone Joint Surg Br. 1990; 72(5):757-760.

29. 3. Chambers IR, Fender D, McCaskie AW, Reeves BC, 
Gregg PJ. Radiological features predictive of aseptic loosening in cemented Charnley femoral stems. J Bone Joint Surg Br. 2001; 83(6):838-842.

30. Baker RP, Squires B, Gargan MF, Bannister GC. Total hip arthroplasty and hemiarthroplasty in mobile, independent patients with a displaced intracapsular fracture of the femoral neck. A randomized, controlled trial. J Bone Joint Surg Am. 2006; 88:2583-2589.

31. Rogmark C, Carlsson A, Johnell O, Sernbo I. A prospective randomised trial of internal fixation versus arthroplasty for displaced fractures of the neck of the femur: functional outcome for 450 patients at two years. J Bone Joint Surg [Br]. 2002; 84- B:183-8.

32. Paul TPW, Burgers, Arnoud R, Van Geene, Michel PJ, Van den Bekerom, Esther MM et al. Total hip arthroplasty versus hemiarthroplasty for displaced femoral neck fractures in the healthy elderly: a metaanalysis and systematic review of randomized trials. International Orthopaedics (SICOT). 2012 36:1549-1560. 